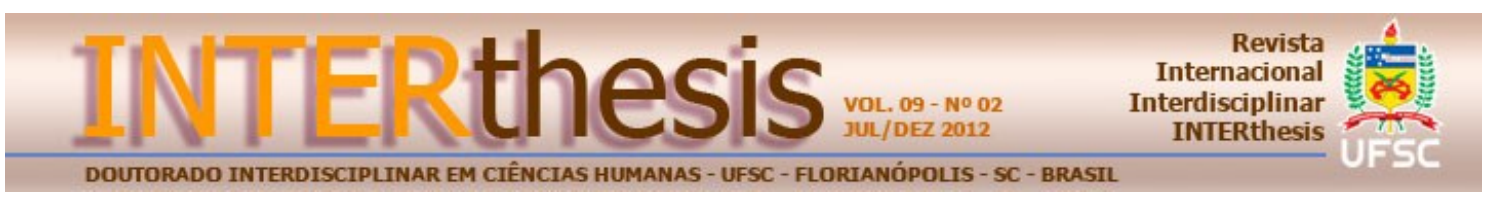

\title{
FORA DE CENA: A LOUCURA, O OBSCENO E O SENSO COMUM ${ }^{1}$
}

\section{OFFSTAGE: MADNESS, THE OBSCENE, AND COMMON SENSE}

\author{
FUERA DE ESCENA: LA LOCURA, LO OBSCENO Y EL SENTIDO COMÚN
}

Angel Martínez-Hernáez ${ }^{2}$

\section{Resumo:}

$\mathrm{Na}$ história europeia, a loucura está associada com dois estados: o movimento e o confinamento. Estes estados aparentemente contraditórios convergem em um estado obsceno, no sentido etimológico da palavra: fora de cena. Neste artigo, baseado em dados etnográficos na rede de saúde mental de Barcelona, argumentase que o "estar obs-ceno" se produz quando a loucura desafia os processos sociais hegemônicos de persuasão que induzem a aceitar padrões de comportamento considerados adequados e a identificação dos pacientes com os interesses dos terapeutas. A loucura não desafia a razão, como normalmente se diz, senão o senso comum entendido como um sistema cultural. A natureza refratária da loucura conduz a uma gestão estigmatizante nos sistemas especialistas que procuram incorporar a experiência dos sujeitos afligidos em categorias nosológicas previsíveis.

Palavras-chave: Loucura. Obs-cenidade. Senso comum. Etnografia. Biopolítica.

\section{Abstract:}

Throughout European history, madness has been associated with two states: movement and confinement. These apparently contradictory states converge in an obscene state, in the etymological sense of the word: offstage. In this article, based on data from ethnographic work in the Barcelona mental health care network, it is argued that "being ob-scene" results when madness challenges hegemonic social processes of inculcation and persuasion that induce acceptance of behavioral patterns considered appropriate, and lead patients to identify with the interests of therapists. Madness defies not reason, as it is widely supposed, but common sense understood as a cultural system. Its refractory nature leads to the stigmatizing management of madness in expert systems that seeks to subsume the experience of affected persons in predictable nosological categories.

Keywords: Madness. Being ob-scene. Common sense. Ethnography. Biopolitics.

\section{Resumen}

1 Este texto toma como referência outros trabalhos anteriores (MARTíNEZ-HERNÁEZ, 1998; MARTÍNEZ-HERNÁEZ, 2000). Quero agradecer a C. Mendoza a leitura atenta deste texto.

2 Doutor em Antropologia pela Universidade de Barcelona, Espanha. Professor Titular de Antropologia da Universitat Rovira i Virgili, Espanha. E-mail: angel.martinez@urv.cat
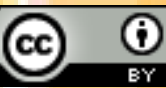

Esta obra foi licenciada com uma Licença Creative Commons - Atribuição 3.0 Não 
En la historia de Europa, la locura ha estado asociada a dos estados: el tránsito y el confinamiento. Aunque aparentemente antagónicos, estos dos estados conforman un estar obsceno, entendiendo este término en su sentido etimológico de fuera de escena. En este texto, y tomando como referencia los datos de nuestro trabajo etnográfico en la red de salud mental de Barcelona, se argumenta que el "estar obsceno" se deriva de la especial refracción de la locura con los procesos de hegemonía, persuasión e inculcación que operan habitualmente en la vida social y, en particular, con su refracción no a la razón, como generalmente se invoca, sino al sentido común entendido como sistema cultural. Esta refracción es la que induce a una gestión estigmatizante de la locura en los sistemas expertos que busca subsumir la vivencia de los afectados en categorías nosológicas previsibles.

Palabras-clave: Locura. Obs-cenidad. Sentido común. Etnografía. Biopolítica.

\section{INTRODUÇÃO}

Na história de Europa e de seus processos civilizatórios (e colonizadores) a loucura vem associada a duas práticas sociais: o trânsito e o confinamento. A primeira destas práticas adquire uma de suas melhores representações no Quixote, onde, como é sabido, o insensato se vê abocado a um trânsito contínuo, pois aquilo que trata de atingir é tão próximo e ao mesmo tempo tão longínquo como a própria fantasia. O confinamento, por sua vez, inclui entre outras modalidades o manicômio como lugar de reclusão (não se sabe bem o quê) da sem-razão, do caos, da falta de senso comum, da desordem, do medo, da diferença, da dissidência, mas que persiste durante séculos como uma forma de controle social. Movimento e reclusão constituem dois atributos aparentemente contraditórios que conformam um "estar obsceno", entendendo esta palavra no sentido etimológico de "fora de cena". Pensemos que enquanto o movimento se converte numa saída forçada ou voluntária do jogo social, o confinamento não deixa de ser uma forma de anulação do direito à cidadania dos afetados.

Como é de esperar, o laço que une movimento com reclusão é o mesmo que vincula a loucura a um saber psiquiátrico que foi considerado "especial" nas suas origens. A psiquiatria é um saber e uma prática sobre a alteridade, ainda que com o tempo essa alteridade tenha sido diluída para constituir um território de estados de anormalidade tão difuso como débil em sua formulação. Estados depressivos e ansiosos, o suposto "risco" ou probabilidade de padecer um transtorno, comportamentos incômodos associados ao jogo, a sexualidade, a agressividade ou a interação social, o mal-estar próprio do ciclo da vida, estados como a perda leve de memória, são situações, entre muitas outras, que com o tempo se converteram 
em estados tratáveis para o saber psiquiátrico, tal como se desprende de qualquer revisão histórica ${ }^{3}$, da implementação mais contemporânea do DSM-IV e dos debates prévios ao ainda inédito e inquietante DSM-V. Se a gestão da psicose foi sempre um exercício de ocultação, a nova gestão das neuroses é principalmente uma tarefa de persuasão para resolver uma suposta anomalia considerada reversível e em seu lugar fazer emergir uma hipernormalidade que vincule o sujeito a uma cultura e economia-política do consumo (MARTíNEZ-HERNÁEZ, 2006). Pelo contrário, a loucura não parece objeto de persuasão ou não ao menos em primeiro lugar. A psicose é um estado que na modernidade não se interpreta como susceptível de entendimento e menos de diálogo. Mais bem, ela costuma gerar um monólogo onde terapeutas, familiares e supostos sensatos acabam encontrando o que procuravam: a sem-razão, a impossibilidade de um vínculo social do afetado, o reflexo da angústia dos supostos sensatos ou as próprias nosologias como noções que acabam gerando uma ideia de doente total que requererá uma terapia total ${ }^{4}$.

O que realmente produz esta necessidade de localizar a loucura fora de cena, como uma imagem que não deve ser vista? O que se esconde na própria ação de esconder? O que se mostra ante esta tentativa de fazer invisíveis estes estados de anormalidade, de negar a sua palavra? É algo tão simples como o axioma krapeliniano que o delírio é a expressão do erro, ou vai além desta afirmação para envolver outras disfunções e curtos-circuitos entre a loucura e a estrutura cultural com suas formas de saber/poder? O objetivo deste texto é precisamente reflexionar sobre a criação da loucura como um objeto obsceno que, a sua vez, redunda na necessidade de toda política e gestão da vida de ser também obscena, de ocultar sua vontade de poder sob um enredo de naturalizações do mundo social que permitam que a vida sentida (identidade) converta-se em alguma forma de identificação ${ }^{5}$ crida e previsível.

\footnotetext{
${ }^{3}$ Ver, entre muito outros, Caponi (2012).

${ }^{4}$ Para uma analise do conceito de "doente total" ver Correa-Urquiza (2010). Para a noção de "terapia total" ver Martínez-Hernáez (2009).

${ }^{5}$ Os conceitos de "identidade" e "identificação" são aqui utilizados como uma variação e adaptação das noções desenvolvidas por Terradas (2004) para falar respectivamente da identidade vivida e a identificação política. Esta última pode entender-se como a alienação da vida, a "reducción y conversión abstracta de una memoria de vida en un signo de pertinencia o estigma político".
} 


\section{A LOUCURA E O NÃO-LUGAR}

Como sabemos por diferentes autores ${ }^{6}$, no século XV emergiu como representação pictórica e literária e também como trágica realidade social a figura da stultifera navis ou Nave dos loucos. Em procura de uma suposta razão perdida os insensatos eram enclausurados em naves e obrigados a descer os rios da Renania em direção à Bélgica ou a remontar o Rin para Jura e Besançon. Ainda que as razões dessa prática são bastante obscuras, Foucault (1985) destaca algumas delas, como o caráter simbólico da água à que são confiados os insensatos: a água é ao mesmo tempo elemento purificador e representação da instabilidade e incertezas associadas à estultícia. Ademais, essa prática responde a certa pragmática pública, pois não deixa de ser uma deportação em massa dos loucos fora do espaço da cidade. A Nave dos loucos é em última instância uma forma sofisticada de confinamento que localiza aos afetados na posição do perpétuo passageiro, na encruzilhada infinita.

Está documentado desde o século XIV que os loucos que produziam alterados públicos ou simplesmente molestavam na cena cidadã, e mais ainda se eram alienados considerados estrangeiros, eram primeiro enclausurados nas "casas de loucos" municipais ou nos hospitais gerais existentes. A Dolhaus do Georhospital de Elbing criada em 1326 ou a Tollkiste de Hamburgo da mesma época são exemplos de casas de loucos criadas ex professo. O Hôtel-Dieu de Paris ou o Holy Trinity em Salisbury (Inglaterra) são exemplos de hospitais gerais que contam com alienados entre seus pacientes desde o século XIV. Desde esses recintos os loucos passavam a ser liberados, enclausurados em prisões ou entregados à sorte da navegação (ROSEN, 1974). Em algumas ocasiões as autoridades municipais os confiavam a marinheiros e mercadores que eram remunerados por sua função de portadores. As insólitas mercadorias eram abandonadas nos lugares de passagem e de mercado onde podiam deambular com certa liberdade até que se iniciava de novo o processo de reclusão e deportação. Também podia ser que, seguindo o modelo de exclusão da lepra existente durante a Idade Média, fossem segregados aos campos exteriores às muralhas ou que, simplesmente, fossem retidos nos

\footnotetext{
${ }^{6}$ Ver Rosen (1974) e Foucault (1985) entre outros. Ver Cabral (2011) para uma versão curiosa do "trem dos loucos" no Brasil.
} 
lugares de passagem, como nas portas das cidades, retornando-os assim ao espaço do trânsito, a esse território de indefinição onipresente na modernidade que Marc Augé (1993) definiu como o não-lugar.

Ainda que Foucault indique que o modelo de controle da loucura baseado na stultifera navis e a exclusão aos lugares de passagem teve um tempo limitado de existência, pelo menos até a instauração do manicômio, um exame atencioso nos mostra que alguns elementos desse sistema persistiram. Em algum momento do desenvolvimento da cidade e do Estado moderno não foi suficiente a biopolítica clássica da loucura e se requereu de uma regulação mais intervencionista para pôr um limite a esse trânsito contínuo. Até que ponto essa nova ordem se deveu ao desenvolvimento do Estado moderno, ao espírito dessa estrutura econômico-política chamada mercantilismo (cameralismo em Alemanha), ao aumento dos fluxos comerciais e por tanto de mercadorias que ocuparam os exteriores abandonados das vilas e cidades ou à emergência de uma lógica estatista, derivada do mercantilismo, que não podia permitir-se a existência de naves de loucos à deriva sem ordem nem concerto, é uma incógnita ainda por despejar. Agora bem, fosse qual fosse o fator determinante na aparição do asilo, não se pode negar a persistência de algumas similitudes com a stultifera navis.

O manicômio instaura um sistema de reclusão sedentário, mas ao igual que os barcos de loucos, supõe a concentração dos insensatos num espaço físico que é purificador e ao mesmo tempo incerto. $O$ efeito purificador da água se supre no asilo com medidas como a chamada terapia moral que inaugurou Pinel ou com tratamentos criados para a "reabilitação" do espírito primeiro e da mente mais tarde. A incerteza, por sua vez, deixou de representar-se agora com o rio dos mil braços e o mar aberto, mas não desapareceu do panorama social, pois o asilo virá intimamente unido no imaginário ao irracional, ao inesperado e também ao sinistro. Porque, o que é um manicômio, senão uma nave dos loucos ancorada nos confins da cidade e despojada de sua simbologia aquática? Tanto a stultifera navis como as casas de loucos que proliferaram nos municípios europeus desde o século XIV podem entender-se como as condições de possibilidade do que Foucault chamou o "grande encerro".

Outra similitude não menos importante é que o modelo asilar, da mesma forma que a stultifera navis, não resolve o problema errante da loucura, senão que simplesmente o contém. Nos manicômios que ainda existem nos países que não 
levaram a cabo ou completado seu processo de reforma psiquiátrica se observa esta luta entre o controle e a mobilidade. Os reclusos passeiam pela instituição com frequência sem rumo fixo ou com uma rotina inflexível, sobem e baixam as mesmas escadas vinte ou trinta vezes ao dia, vão do quarto ao refeitório, do refeitório à sala, da sala ao pátio, do pátio ao refeitório e do refeitório ao quarto de novo (CAUDILL, 1958; DUNHAM et al., 1960; GOFFMAN, 1988; FERREIRA e MARTíNEZHERNÁEZ, 2003). Quando passeiam pelo pátio caminham de um muro a outro do recinto, cinco vezes, dez vezes, vinte vezes. Se não podem mover-se fisicamente suprem esta falta evadindo-se psicologicamente. É como se seu movimento físico e sua evasão mental substituíssem o vaivém da stultifera navis. Se a Nave dos Loucos assumia em si mesma o movimento e assim em certa medida neutralizava, a estaticidade do manicômio acaba estabelecendo um modelo de contenção claramente forçado que se reflete nos itinerários insistentes dos reclusos dentro da instituição.

Os modelos posteriores de desospitalização e desinstitucionalização baseados numa estrutura de dispositivos diversos que oscilam entre as unidades de psiquiatria dos hospitais gerais, onde os pacientes são internados durante o tempo de crise, e os centros de reabilitação psicossocial, onde esperam sua sempre postergada autonomia, passando pelos hospitais de dia e outros dispositivos da rede assistencial não puderam resolver o problema da mobilidade dos afetados, que é também o problema da sua não pertinência social e sua atribuída obscenidade. Ainda que já desde os anos cinquenta do século XX se observa uma maior sofisticação dos tratamentos, fundamentalmente com a entrada no palco dos neurolépticos, o problema do trânsito não foi solucionado, senão que inclusive se acrescentou. A camisa de força que impedia o movimento dos braços deixou passo ao que foi chamado, creio que com acerto, "camisa de força química".

Aparentemente já não se precisam mais os muros físicos do asilo, pois os novos fármacos geram "muros", desta vez neuroquímicos, que facilitam a contenção inibindo alguns dos chamados sintomas floridos da psicose, como o delírio e as alucinações. No entanto, esse tipo de tratamento, além de produzir efeitos secundários adversos (parkisonismo no caso dos antipsicóticos típicos e síndrome metabólica no caso dos atípicos: antes, rígidos... agora, obesos...), não permitiu um controle além da dicotomia trânsito/confinamento. Os afetados continuam deambulando de um a outro lugar sem rumo fixo. Concentram-se, curiosamente, nos 
espaços de trânsito e de não-lugar como as rodoviárias, as estações de trens, os centros das cidades e os parques. Por outro lado, os profissionais tratam de encontrar uma solução a fenômenos como o chamado revolving-door ou porta giratória, que não é outra coisa que o processo contínuo de internação e alta no que se veem submetidos os afetados. É como se estivéssemos ante uma variação da stultifera navis e seus jogos de exclusão aos territórios de passagem, já estejam esses jogos baseados na ideia do enfermo como sujeito contaminante, já estejam construídos a partir da reiteração de gestos e comportamentos que sedimentam a marginação dos afetados ao território do limbo social.

Até certo ponto, a dialética entre movimento e contenção guarda a lógica simples da liberdade e a reclusão. Tanto a exclusão às zonas de passagem e a Nave dos loucos, como o encerro que instaura o manicômio ou o modelo de desospitalização gerado nas últimas décadas, têm em comum que se levam a cabo a costa da consciência e vontade do afligido. Sob a desculpa da incapacidade mental dos afetados, esses três modelos se unificam em sua grande capacidade coerciva. Por exemplo, é frequente que sob o modelo de desospitalização não se comunique ao afetado o diagnóstico de sua doença. A presunção de que a loucura vem unida à confusão e ao erro gera uma relação de poder onde "diga o que diga ou faça o que faça" o afetado terá tudo sempre em contra. Tanto a afirmação da loucura como sua negação sempre responderá às expectativas do terapeuta. Uma vez dentro do catálogo dos loucos, o círculo se fechou ante qualquer argumento. Em seu lugar se disporá uma prática de vida tutelada que com dificuldade poderá escapar de uma vigilância moralizadora.

\section{SENSO COMUM E SENTIDO OBSCENO}

Durante aproximadamente um ano, entrevistei a Babu dois dias à semana com o propósito de elaborar sua história de vida. Naquele momento Babu estava ingressado num residencial terapêutico para psicóticos crônicos de Barcelona no qual convivia com outros vinte pacientes que também atuaram, ainda que em menor grau, como informantes na minha pesquisa etnográfica. É importante sublinhar que dentro do repertório de recursos assistenciais para o tratamento dos afetados, os residenciais terapêuticos, junto aos apartamentos assistidos, são entendidos como um dos níveis mais próximos à chamada inserção ou reinserção dentro da 
comunidade, ainda que ninguém se encarregue de definir que mistério é isso da "comunidade". Neste contexto, Babu e seus colegas dispunham de uma maior liberdade de movimentos que em outros dispositivos assistenciais.

A jornada de Babu decorria entre o residencial e umas horas de dedicação a um ateliê de reabilitação que regia a mesma fundação que geria a residência. Tratava-se de um ateliê que combinava diferentes atividades como a pintura, a encadernação e pequenos trabalhos de montagem, e que incluía um quiosque/papelaria que abria suas portas ao público em general. Babu estava geralmente à frente da caixa e em coato com o público. De fato, uma parte importante das conversas que tivemos se levaram a cabo na papelaria, bem como num pequeno escritório habilitado para as entrevistas terapêuticas.

Devo confessar que para Babu (e às vezes também para mim) resultava complicado estabelecer uma distinção entre o que é uma entrevista etnográfica e o que supõe uma relação terapêutica. Dado que não sou psiquiatra nem psicólogo, uma das questões que tratava de esclarecer desde o princípio a minha condição de antropólogo ou etnógrafo que simplesmente quer escutar a sua história, mas em modo algum realizar um tratamento psicoterapêutico. No meu ponto de vista, a entrevista clínica diferencia-se da entrevista etnográfica porque na primeira o profissional se posiciona no papel do saber ou suposto-saber, e que na segunda o pesquisador adota uma posição mais própria do não-saber para poder desvelar os significados nativos. Em caso contrário, seria impossível dar conta do saber do outro e menos aplicar um relativismo metodológico característico da antropologia que permitisse encontrar um código dependente não tanto do pesquisador como do pesquisado. Se se prefere em palavras de um autor como Geertz (1987), o objetivo da antropologia não é dar respostas a nossas perguntas mais profundas, senão darnos acesso a respostas dadas por outros.

Apesar das aclarações que realizei a Babu e aos meus informantes sobre qual era o objetivo de meu trabalho, na prática era difícil para eles estabelecer uma distinção entre uma terapia de orientação psicanalítica e a entrevista etnográfica. Embora possamos pensar que existem claras diferenças entre as intervenções pontuais do terapeuta orientando a cura e as perguntas mais explícitas do etnógrafo e encaminhadas à simples consecução de informação, o certo é que ao responder a minhas questões Babu se obrigava a um trabalho de revisão autobiográfica. Nesse 
palco de confusões se levaram a cabo minhas entrevistas com Babu. Mas conheçamos um pouco sua história.

Babu explicou-me que era um konkani que pertencia à minoria católica da Índia e que sua família tinha origens aristocráticas. Narrou-me que tinha tido uma infância marcada pela tortura contínua infringida por um pai alcoólico. A tortura consistia em disparar cada noite, apontando a sua cabeça de menino, uma escopeta sem munição e em castigos corporais que à manhã seguinte eram obviados ou omitidos por todo o grupo doméstico como se nada tivesse acontecido. De forma semelhante a essa lógica que Michael Taussig (1995) especificou em seus escritos sobre o papel do silêncio e a negação da tortura na amplificação e gestão do terror, Babu, seus irmãos e sua mãe viviam sob a imprevisão da tortura e a tortura da imprevisão. Contou que foi um menino esforçado na escola até a idade de quinze anos em que adoeceu de febre tifoide, que teve dificuldades para relacionar-se com as mulheres devido a sua timidez e que emigrou a Londres com o propósito de estudar uma carreira universitária. Lá conheceu a sua esposa com quem veio posteriormente a residir e a trabalhar em uma cidade próxima a Barcelona. Seu emprego consistia em ser executivo de uma conhecida multinacional americana.

Pelo que me explicou, seu transtorno emergiu de forma abrupta em Barcelona. De repente começou a ter dificuldades para concentrar-se no trabalho. A essa dificuldade se seguiu um sentimento intenso de "depressão" e uma "necessidade de ficar em casa" afastado de todo contato social e rememorando os problemas de tortura de sua infância. O processo está melhor explicado nas suas próprias palavras:

Lembrava-me das noites de tortura com meu pai...sempre esperando que me matasse de uma vez e não me matava. Pensei que, como tinha sofrido tanto, eu era Jesus Cristo. Às vezes, quando era menino eu fantasiava que era um grande futebolista ou um tenista e a gente me aclamava; que era um grande cientista e tinha feito uma grande descoberta ou que eu era sueco e tinha sido adotado por uns sujos índios. Agora pensava também que eu era muito importante. Eu não estava bem no trabalho. Tinha muitos nervos e paralisia cerebral, não podia trabalhar e tinha que ficar mais tempo do que os demais. Sabia que me queriam despedir do trabalho, mas eu me pus mal dos nervos antes e peguei a baixa.

Os últimos dias de trabalho eu pensava tolices como que os chefes norteamericanos vinham a Barcelona e me colocavam de diretor. Meu chefe então se ajoelhava aos meus pés e me pedia perdão. Todos me elogiavam. A verdade é que quando passeava pelo escritório me parecia ouvir vozes que me diziam [torcendo]: 'chefe, chefe'. Depois pensava que era o presidente de todas as multinacionais estrangeiras em Barcelona e que 
vinham pedir-me trabalho e favores. Quando ia pela rua, pensava que as mulheres que vestiam de azul e branco queriam ser amantes minhas e os homens vestidos assim, meus colaboradores. O presidente Bush tinha baixado de sua poltrona para dar-me uma oportunidade porque eu era mais inteligente. Quando via a televisão americana, por satélite, pensava que se referiam a mim porque tinham posto um dispositivo eletrônico em minha casa para proteger-me dos atentados. Mas já ser presidente de USA não era suficiente, e então tinha que ser rei de todo mundo, e como eu tinha sofrido tanto de menino é como se tivesse sido crucificado por meu pai; porque eu nunca ouvi uma história como a minha em nenhuma parte. Aquilo foi terrível, uma tortura contínua. Depois tinha voltado à vida para ajudar a toda gente. Deixei de ser Babu... para ser Jesus Cristo.

A experiência de Babu, ainda que íntima, tinha um impacto importante em seu comportamento no trabalho e na relação com seus colegas. Dificilmente alguém que acredita ser o presidente dos Estados Unidos ou Jesus Cristo pode passar despercebido num meio trabalhista. Razão pela que em seguida Babu se viu abocado primeiro à perplexidade de seus colegas e mais tarde à mais absoluta marginação até sua baixa por doença e o início do tratamento psiquiátrico.

De fato, em relatos como os de Babu se observa que um dos espaços de maior rejeição do delírio e das manifestações da loucura por extensão é precisamente o contexto trabalhista, núcleo duro da praticidade que não tolera tais irrupções. A diferença de outros contextos culturais, onde esse tipo de manifestações não gera uma rejeição social, ou ao menos não da mesma intensidade ou envergadura, na cultura do capitalismo se sacode rapidamente a loucura para as margens, uma autêntica expulsão da cena que como vimos já estava presente na época da stultifera navis. Evidentemente, essa negação do lugar é uma prática social em si mesma, de tal forma que o não-lugar adquire caráter de lugar, ainda que isso sim, um lugar especial, um lugar associado a uma identificação forte (as nosologias e suas práticas derivadas de controle da vida) que reduz, se é que não anula, outras possibilidades de ser e, por tanto, de cidadania ${ }^{7}$. Agora bem, por que se produz essa exclusão da cena? É evidente que a experiência de Babu adota formas não aceitas socialmente, mas contra o que atenta essa experiência para merecer a condenação à obscenidade?

É um lugar comum localizar a loucura em oposição à razão ou inclusive à racionalidade, entendendo a primeira como qualidade e a segunda como sistematização dessa qualidade. Frente a uma ideia de "razão" ahistórica que

\footnotetext{
${ }^{7}$ Ver Belloc (2011).
} 
permite uma valoração correta das coisas, se oporia o defeito do juízo, a confusão da realidade interna com a externa, a falta de discernimento dos desejos subjetivos, enfim: a loucura como sem-razão indomável. Agora bem, o problema é que dificilmente podemos entender que algum contexto terapêutico possa ser a materialização da racionalidade. A análise das práticas de contenção, reabilitação e tratamento na maioria dos contextos nos mostra que a loucura parece opor-se mais do que a essa entidade abstrata chamada razão ao plano mais cotidiano do senso comum, entendendo este nos termos que Clifford Geertz utiliza em "Common sense as a cultural system" (1983).

No mencionado texto, o antropólogo de Princeton define o senso comum como um sistema cultural que se caracteriza pelos seguintes atributos: a naturalidade, a praticidade, a transparência, a assistematicidade e a acessibilidade. Vale a pena sublinhar, ainda que possa parecer óbvio, que se trata de atributos que não são das coisas, senão atribuições do senso comum às coisas. Precisamente no jogo de atribuições ou não atribuições e de interpretações das presenças e ausências dessas atribuições onde parece definir-se, a meu juízo, a construção social da loucura. Entretanto, analisemos em maior profundidade.

Geertz destaca que a qualidade mais clara do senso comum é a naturalidade, entendendo esta em seu significado de obviedade. Como é de esperar, essa ideia de naturalidade não se aplica ao terreno de todas as coisas e representações, senão que focaliza seu atendimento em determinadas matérias que sob essa luz aparecerão como evidentes. Ainda que Geertz não o indique, não se precisa ser muito perspicaz para interpretar que no fundo a naturalidade é um atributo de qualquer sistema cultural, pois é o que permite a construção do que esse autor definiu como a "aura de factualidade" dos fenômenos; essa condição pela qual as representações aparecem como inequivocamente reais para os atores sociais. Provavelmente uma maneira de definir tal condição é o princípio cultural de que as coisas são como são porque respondem a uma lógica preestabelecida (enquanto natural) que é legítima.

Pois bem, se analisamos o relato de Babu, observamos que aparecem claramente dois tipos de registro. No primeiro os acontecimentos se produzem com uma lógica similar à obviedade do senso comum: se sofreu tortura do seu pai é lógico compreender que Babu esteja afetado, que tenha problemas para concentrarse ou que fantasie que é um menino sueco adotado. Afinal de contas este é o tipo 
de fantasias que Freud (1981:1361) chamou uma vez "novela familiar do neurótico" (Familienroman), ou seja, pensar que se é filho de outros pais, que foi adotado e fabular a partir daqui todo um mundo de relações familiares, é provavelmente inerente à capacidade imaginativa de todo ator social, ao menos na mesma medida que a neurose era para Freud. Mas essa naturalidade da história de Babu se quebra por um segundo registro que se inicia nesse "Os últimos dias de trabalho pensava tolices..." e que lhe dirige a pensar que é o presidente dos EUA e posteriormente Jesus Cristo. O que se conhece como delírio se opõe à obviedade e naturalidade do senso comum. O que alerta aos familiares, afins ou colegas de trabalho de que um ator como Babu se revirou é essa falta de obviedade, ou seja, de ruptura com a aura de factualidade do sistema cultural. Nas diversas inflexões do senso comum (ou dos sensos comuns em jogo) seria possível ver virgens e escutar a voz de Deus ou desmascarar imaginativamente o senso comum hegemônico e sua naturalização do mundo, como assim se faz desde alguns movimentos artísticos. No entanto, se algo caracteriza o delírio é uma ruptura subjetiva, onde paradoxalmente o biográfico e o inacreditável se unem para mostrar o arbitrário que articula toda naturalização, para despir os artifícios de um mundo social de convenções. Se se prefere utilizar um argot estruturalista, é como se o acontecimento navegasse contra toda estrutura fazendo explodir a aura de factualidade do sistema cultural.

A especificidade da experiência de Babu também se confronta claramente contra o resto dos atributos do senso comum. Seu mundo ficcional onde se converte em chefe de todas as empresas multinacionais norte-americanas de Barcelona e mais tarde em presidente dos Estados Unidos dificilmente pode guardar sintonia com o princípio de praticidade. Menos ainda podemos acercar a experiência de Babu às especiais conotações de "astúcia" e de "capacidade para fazer prosperar os projetos" que segundo Geertz devem interpretar-se sob este atributo.

A fabulação de Babu também é chave para entender a ausência em seu discurso de outros atributos de senso comum como a transparência (thinness no original). Se, como diz Geertz, a transparência pode definir-se com o verso de Butler de que "tudo é o que é e não outra coisa" ("everything is what it is and not another thing"), o relato de nosso informante bem pode resumir-se na ideia de que "tudo não é o que é, senão outra coisa". Uma ideia que é aplicável ao seu mundo subjetivo e a sua certeza de que ele não é quem é (um executivo e engenheiro de uma multinacional) senão outra coisa (Presidente dos EUA, Jesus Cristo), mas também a 
sua interpretação da realidade social, já que ali também o que é (transeuntes que vestem de azul e branco) é claramente outra coisa (suas amantes, no caso das mulheres, e seus colaboradores, no caso dos homens).

Seguidamente temos o atributo da assistematicidade (immethodicalness no original) que remete, ainda que Geertz não o diga exatamente assim, à flexibilidade de toda asseveração e ideia sobre as coisas, a essa elasticidade - e agora sim dito por Geertz - que se descobre em versos como o de Whitman: "Me contradigo a mim mesmo, ou seja, que me contradigo. Eu contenho multidões" ("I contradict myself, so I contradict myself. I contain multitudes"). Um princípio que é claramente contraditório com a experiência de Babu, pois uma característica do delírio é a falta de maleabilidade e a rigidez do sistema de crenças e convicções.

Finalmente temos a qualidade da acessibilidade, que nos diria algo como que o senso comum é propriedade geral de todos os atores sociais, ou ao menos de uma parte importante deles, pois, como nos indica Geertz, "qualquer pessoa com suas faculdades razoavelmente intactas pode chegar a conclusões de senso comum" (1983:113). Não é gratuito que o próprio Geertz (ou seu senso comum) ofereça-nos esta oposição entre senso comum e loucura, ainda que só seja como uma anotação apressada e quase inconsciente. A experiência de Babu, por exemplo, põe em evidência como à comunidade dos juízos pode opor-se uma idiossincrasia que implica uma dose importante de inacessibilidade.

Em síntese, na loucura podemos observar uma artificialidade narrativa que se opõe à naturalidade, uma fantasia que se contrapõe à praticidade, uma codificação que se contradiz com a ideia de literalidade dos fenômenos, uma rigidez que replica à flexibilidade e assistematicidade necessárias para manejar-se cotidianamente e uma idiossincrasia que tem uma tendência ao inacessível. Dito em outras palavras, situações como as de Babu quebram as bases do senso comum para opor uma espécie de "sem-senso" comum ou sentido obsceno.

A modificação desse sentido obsceno é o objetivo fundamental, ainda que tácito, da maioria de dispositivos assistenciais encarregados do tratamento e reabilitação das pessoas afetadas por uma psicose. Esses recursos atuam como autênticas escolas de senso comum que tratam de recompor nos atores a aura de factualidade das ações e representações sociais para que se convertam em sujeitos solventes desde o ponto de vista social. É por isso que esses recursos não podem escapar a uma função moralizante e moralizadora, ainda que as maiorias das 
terapias se pensem a si mesmas como intervenções alheias ao mundo social e moral. É por isso que os profissionais nesses casos não procuram estratégias que permitam aos afetados associar o seu relato contracorrente do senso comum a uma atividade crítica e/ou reflexiva, a uma função social, por exemplo, que se derive de sua particular visão do mundo. Não, simplesmente isto não é possível nem considerado desejável. A loucura é temida por despir os artifícios do senso comum, incluindo o mais fundamental que é o que permite sua naturalização. Não há lugar para uma função social da loucura, por exemplo, para repensar o arbitrário de nosso mundo social. Isso significaria uma aceitação da loucura como parte da cena, como recurso com sentido. Mas não, a maioria das terapias não procuram dialogar ou dar espaço ao relato psicótico, senão domá-lo como uma anomalia, domesticá-lo. Ainda que o sucesso dessa missão seja sempre escasso ou nulo.

No contexto assistencial no qual se encontrava Babu não se favorecia que os afetados desenvolvessem sua própria visão do mundo, e menos de forma crítica, criativa e reflexiva. Mais bem se tratava que assumissem e participassem das convenções sociais mais estereotipadas e normatizadas sem questioná-las. Daí que os terapeutas não considerassem oportuno que seus pacientes lessem livros de esoterismo, participassem de grupos religiosos minoritários ou que refletissem sobre problemáticas abstratas. Sobre este último particular observei uma curiosa discussão entre uma psiquiatra e seu paciente devido a que este último, que tinha sido diagnosticado de esquizofrenia um ano antes, começou a estudar filosofia numa universidade local. Enquanto o afetado explicava seu interesse por algumas problemáticas que propõe a filosofia sobre o sentido da existência ou o ser das coisas, a profissional Ihe exigia que abandonasse este tipo de estudos e se dedicasse a outros mais afeiçoados à realidade prática. Desta maneira a terapeuta reconduzia ao afetado não ao terreno da racionalidade, senão ao domínio mais elementar, prático e acessível do senso comum.

As conversas que geralmente se adotam nas sessões de terapia grupal também mostram uma preferência por temas considerados práticos e elementares, como os transportes públicos, como conseguir emprego ou o preço das coisas no mercado. Um dos objetivos é gerar uma visão de senso comum que possa ser compartilhada pelos diferentes indivíduos que participam na sessão. É como tentar recuperar os pedaços individuais de senso comum dos diferentes participantes para recompor um senso comum coletivo que possa ser assumido individualmente. Por 
exemplo, numa sessão monográfica sobre os transportes públicos que realizaram numa das instituições onde eu exercia de pesquisador, um dos afetados, Emilio, afirmou que os ônibus de dois andares não eram seguros e volcavam continuamente, pelo que se negava a subir nesse tipo de veículo, e mais se levavam números ímpares, pois ele nasceu num dia, mês e ano com número par, por tanto, em sua lógica par significava vida e ímpar morte. O terapeuta procurou a resposta crítica no resto dos afetados, que coletivamente introduziram argumentos como que os engenheiros e fabricantes de ônibus já têm em conta os requisitos de segurança na hora de desenhar os ônibus de dois andares ou que não se tinha notícia de que esses veículos volcassem mais do que outros. Mas como na discussão começaram a aparecer argumentos do tipo "o destino está escrito nos números" ou "quem pode assegurar-nos que esses ônibus não se volcarão alguma vez", o profissional começou a fazer questão de que tinham que ser práticos e aceitar que se as coisas são como são, isto é, se os ônibus de dois andares circulam pela cidade, é por algo. Desta maneira o terapeuta orientava a Emilio a uma atitude de assunção da realidade social e, por tanto, a aceitar a aura de factualidade das representações e artefatos culturais. De fato, os terapeutas utilizam dois mecanismos para recompor o senso comum dos afetados. O primeiro é o sistema explícito da negociação/coerção com o paciente mediante o uso de lógicas como a de castigo/recompensa. $O$ segundo é a busca de uma identificação dos afetados com os juízos dos próprios terapeutas que, como é evidente, representam aqui a voz do senso comum. Há que sublinhar que ambas as práticas são de sucesso muito limitado devido aos sentidos idiossincrásicos ancorados nos afetados e sua tendência a desculturação, a desconstrução dos códigos culturais que permitem naturalizar o mundo.

Nas sessões grupais a tática da identificação se leva a cabo mediante a motivação dos pacientes para que respondam e contradigam aquelas afirmações que não são consideradas práticas e de senso comum, como asseverar taxativamente que os ônibus de dois andares volcam ou, como apontava outro de meus informantes, que há barcos pagos pelo Estado encarregados de armazenar homossexuais e dissidentes para depois abandoná-los em alta mar. Uma simples mirada por parte do terapeuta àqueles pacientes que ele considera mais "recuperados" e que se supõe que podem emitir juízos mais próximos ao senso comum, pode servir para que estes iniciem uma série de comentários críticos próximos às expectativas do terapeuta. Desta maneira, estabelece-se entre o 
conjunto de afetados uma hierarquia de proximidades ao terapeuta que procura obediências e também mimetismos. Mas, para que isso funcione, o terapeuta tem que estabelecer previamente uma relação de transferência ou idealização que é absolutamente necessária para que os afetados se identifiquem com os seus interesses (ou talvez desejos?), pois sem este vínculo dificilmente se pode fazer uso do recurso do "profissional decepcionado" ante os juízos bizarros dos pacientes.

Nas sessões individuais não se pode contar com a ajuda de outros pacientes que exerçam de voz vicária dos profissionais, mas sim com os supostos fragmentos de "senso comum" do afetado, bem como com a posição do terapeuta exercendo de sujeito e personificação desse sentido. Não obstante, é fácil que se quebre a confiança entre ambos. O profissional insistirá ao paciente em que confie no tratamento, em que se deixe guiar. O paciente é provável que pense que dificilmente poderá confiar em quem a sua vez não confia nele ou nela. O usuário novo poderá ser mais explícito na hora de narrar suas experiências, seus delírios, suas alucinações, mas logo observará que isso supõe um alto custo, como o aumento da medicação, a desconfiança do terapeuta e o pânico dos familiares. Assim poderá passar o tempo, até que o paciente opte por narrar aquilo que considera que o terapeuta espera escutar. Dar uma imagem de senso comum, de sujeito domesticado que já não mostra traços de sentidos obscenos, que atua criticamente contra essa experiência que um dia teve. Esta é, por exemplo, a atitude que, segundo me confessou, Babu tinha com os profissionais. Já não tinha confiança para explicar sua experiência, só relatos miméticos com as supostas expectativas do terapeuta. Narrativas colonizadas, de convenção, que ocultassem o inacreditável, o impensável, que permitissem recuperar um pequeno lugar na cena social ou já, nem isso, que ao menos outorgassem tranquilidade e comodidade na vida cotidiana.

É incontestável que toda aceitação do senso comum por parte dos afetados deve surgir para o terapeuta de uma crítica dos próprios delírios e fantasias. Mas, ante a incapacidade manifesta de criar uma hegemonia de senso comum, a persuasão perde sua capacidade como instrumento biopolítico para deixar passo a uma ocultação que opera tanto no nível das práticas terapêuticas como dos próprios afetados. A constatação de uma melhoria clínica ou a mais questionável "cura" da psicose passam pelo reconhecimento por parte do profissional de que se assumem juízos de senso comum e de que estes são materializados em práticas cotidianas como pegar o ônibus, manter a higiene pessoal e a proposição de metas 
alcançáveis. Além de constatar que o afetado superou sua tendência ao delírio. Em realidade, os centros assistenciais se convertem em palcos de contínua luta entre a desculturação própria da loucura e o senso comum. Uma desculturação que reafirma aos profissionais no senso comum e um senso comum que demonstra a arbitrariedade de sua estrutura quando se opõe à desculturação. Daí, provavelmente, tanto a imagem cultural de genialidade e sutileza crítica da loucura contra o statu quo, como grande parte das críticas aos tratamentos psiquiátricos como sistemas coercivos.

\section{CONCLUSÕES}

A loucura é uma voz fora de cena em nossos contextos sociais e terapêuticos. Como um relato que deve domesticar-se, o delírio deve ocultar-se mediante procedimentos psicofarmacológicos e psicoterapêuticos para que ressurja depurado e adaptado ao senso comum. Esta tarefa é, no entanto, um impossível em si mesmo que orienta a uma corrente de fracassos reiterados, já que a loucura é refratária aos processos de hegemonia e de persuasão. É por isso que essa gestão cega da vida consome a usuários, profissionais e familiares. Uma gestão que se oculta a si mesma como tal, por não citar aqui suas perversões associadas à preeminência do management sobre o sofrimento, da nosologia sobre a vida, da identificação burocrática sobre a identidade vivida. O problema não está no lado do sofrimento de quem delira, senão em nossa incapacidade para oferecer um lugar social a um tipo de experiência humana que está aí e, lamentavelmente, veio para ficar. Toda doença, transtorno ou sofrimento não é só o que é em si, senão o que se faz com isso, além de que o ser em si mesmo não possa despojar-se de ser num contexto. Paradoxalmente, a loucura é numa sociedade que quer ocultá-la enquanto a constrói como anomalia; isto é: enquanto a socializa como não lugar social criando homens e mulheres sem história. 


\section{REFERÊNCIAS}

AUGÉ, M. Los “no lugares" espacios del anonimato. Una antropología de la sobremodernidad. Barcelona: Gedisa, 1993.

BELLOC, M. Homem sem história. A narrativa como criação de cidadania. Tese de doutorado, Universitat Rovira i Virgili. 2011. Disponível em:

http://www.tdx.cat/bitstream/handle/10803/32220/HOMEM-SEM-

HIST\%C3\%93RIA\%20-\%20Marcio\%20Mariath\%20Belloc.pdf?sequence=1

CABRAL, K. Artesãos da saúde. Saúde mental e participação social em Porto Alegre. Tese de doutorado. Universitat Rovira i Virgili. 2011. Disponível em: http://www.tdx.cat/bitstream/handle/10803/32218/tesi.pdf?sequence=1

CAPONI, S. Loucos e degenerados. Uma genealogia da psiquiatria ampliada. Rio de Janeiro: Editora Fiocruz. 2012.

CAUDILL, W The Psychiatric Hospital as a Small Society. Cambridge: Harvard University Press. 1958.

CORREA-URQUIZA, M. Radio Nikosia: la rebelión de los saberes profanos. Tese de doutorado, Universitat Rovira i Virgili. 2010. Disponível em:

http://www.tdx.cat/bitstream/handle/10803/8437/Tesi.pdf;jsessionid=6F6D93792EB0

ADA176706603C5A8F2E7.tdx2?sequence=1

DUNHAM, W.; WINBERG, K. The Culture of the State Mental Hospital. Detroit: Wayne State University. 1960.

FERREIRA, L. M.; MARTíNEZ-HERNAÉZ, A. Ulisses, Greta y otras vidas. Tiempo, espacio y confinamiento en un hospital psiquiátrico del Sur de Brasil. Cuadernos de Psiquiatría Comunitaria (3): 2003, 1:59-70.

FOUCAULT, M. Historia de la locura en la época clásica. México: FCE. 1985.

FREUD, S. La novela familiar del neurotico. Obras Completas. Madri: Biblioteca Nueva, 1981, pp. 1361-3.

GEERTZ, C. Local Knowledge. Further Essays in Interpretive Anthropology. New York: Basic Books, 1983.

GEERTZ, C. La interpretación de las culturas. Barcelona: Gedisa. 1987.

GOFFMAN, E. Internados. Ensayos sobre la situación social de los enfermos mentales. Buenos Aires: Amorrortu editores, 1988.

MARTÍNEZ-HERNÁEZ, A. Antropología versus Psiquiatría. El síntoma y sus interpretaciones. Revista de la Asociación Española de Neuropsiquiatría, vol. XVIII, n. ${ }^{\circ} 68,1998$, pp. 645-659.

MARTÍNEZ-HERNÁEZ, A. ¿Has visto cómo llora un cerezo? Pasos hacia una 
antropología de la esquizofrenia. Barcelona: Publicacions de la Universitat de Barcelona, 2000.

MARTÍNEZ-HERNÁEZ, A. La mercantilización de los estados de ánimo. Política y Sociedad 43(3):43-56, 2006.

MARTÍNEZ-HERNÁEZ, A. Más allá de la rehabilitación psicosocial. Cadernos Brasileiros de Saúde Mental, 1 (1), 2009. Disponível em:

http://periodicos.incubadora.ufsc.br/index.php/cbsm/article/view/999

ROSEN, G. Locura y sociedad. Madrid: Alianza. 1974

TERRADAS, I. La contradicción entre identidad vivida e identificación jurídicopolítica. Quadernos de I'Institut d'Antropologia, 20: 63-79, 2004.

TAUSSIG, M. Un gigante en convulsiones. El mundo humano como sistema nervioso en emergencia permanente. Barcelona: Gedisa, 1995.

Dossiê:

Recebido em: Setembro/2012

Aceito em: Outubro/2012 